\title{
Correction to: Zero Tolerance for Genital Mutilation: a Review of Moral Justifications
}

\author{
Brian D. Earp ${ }^{1}$ (1)
}

Published online: 5 April 2021

(C) Springer Science+Business Media, LLC, part of Springer Nature 2021

Correction to: Current Sexual Health Reports (2020)

12:276-288.

https://doi.org/10.1007/s11930-020-00286-0

Reference 34 in the Original Article Unfortunately Is Incorrect. The Correct Reference Is "Earp BD, Shahvisi A, Reis-Dennis S, Reis E. The need for a unified ethical stance on child genital cutting. Nurs Ethics, in press."

Publisher's Note Springer Nature remains neutral with regard to jurisdictional claims in published maps and institutional affiliations.

The online version of the original article can be found at https://doi.org/ 10.1007/s11930-020-00286-0

Brian D. Earp

brian.earp@yale.edu

1 Yale University and the Hastings Center, 2 Hillhouse Avenue, New Haven, CT, USA 